\title{
Incidence and Risk Factors of Acute Kidney Injury in Acute Stroke - in a Tertiary Care Hospital
}

\author{
Ray $\mathrm{NC}^{1}$, Chowdhury MAA ${ }^{2}$, Muqueet $\mathrm{MA}^{3}$, Hasan $\mathrm{MJ}^{4}$, Roy $\mathrm{AS}^{5}$, Sarkar $\mathrm{SR}^{6}$
}

\begin{abstract}
Acute kidney injury (AKI) is a common complication after acute stroke. Multiple additional risk factors are also responsible for development of AKI during acute stroke. This cross sectional observational study was conducted with a total of 240 newly detected computed tomography (CT) confirmed acute stroke patients in Mymensingh Medical College Hospital with an aim to find out the incidence and risk factors of AKI in acute stroke. In this study, AKI developed in $15.42 \%$ of all types of acute stroke and more commonly in haemorrhagic stroke than in ischaemic stroke $(23.44 \%$ vs. $12.50 \%, P<0.05)$. AKI was found more frequently $(54.05 \%)$ in old $>60$ years age group and in male patients $(17.93 \%$ vs. $11.58 \%$ \& $P>0.05)$. Again, AKI developed most commonly in chronic kidney disease (CKD) $(33.33 \%, P<0.05)$ and then in diabetes mellitus (DM) $(31.03 \%, P<0.05)$, in ischaemic heart disease (IHD) $(28.11 \%, \mathrm{P}<0.05)$, in hypertension $(21.14 \%, \mathrm{P}<0.05)$, in previous stroke (15.22\%, $P>0.05)$, in dyslipidaemia (13.33\%, $P>0.05)$, and in smoker $(9.89 \%, P>0.05)$. Family history of $(\mathrm{H} / \mathrm{O}) \mathrm{DM}$ was present in $30.00 \%(\mathrm{P}>0.05)$ and that of hypertension and kidney disease was present in 24.44\% ( $P>0.05)$ and $25.00 \%(P>0.05)$ of stroke patients, respectively. Among the AKI patients, majority (70.27\%) had hypertension and $37.84 \%$ had CKD, $29.73 \%$ had IHD. DM and smoker were $24.32 \%$ of each. Family $\mathrm{H} / \mathrm{O}$ of hypertension, DM and kidney disease was present in $29.73 \%, 16.22 \%$ \& $13.51 \%$ of AKI patients, respectively. So, this study had identified several important risk factors of AKI, in particular age, sex, smoking, hypertension, DM, IHD, CKD and types of stroke. So, the risk score could be easily calculated to predict the risk of AKI in stroke patients. And thus to prevent the development of $A K I$ is of utmost importance to reduce the related morbidity and mortality of acute stroke patients. A multicenter nationwide intensive research is needed to identify the precise mechanism, risk factors, their relation and actual outcome of $\mathrm{AKI}$ that develop in patients with acute stroke.
\end{abstract}

CBMJ 2019 January: vol. 08 no. 01 P: 12-18

Key words: Acute Kidney Injury, Acute Stroke, Ischaemic stroke, Haemorrhagic stroke.

\section{Introduction}

Acute Kidney Injury (previously termed as acute renal failure) was previously defined as - "an abrupt decline in renal function which is usually reversible, developing over a period of hours to days". ${ }^{1}$ But recently $A K I$ is defined as any of the followings -

- $\quad$ Increase in SCr by $\geq 0.3 \mathrm{mg} / \mathrm{dl}(\geq 26.5$ $\mu \mathrm{mol} / \mathrm{l})$ within 48 hours; or

- Increase in $\mathrm{SCr}$ to $\geq 1.5$ times baseline, which is known or presumed to have occurred within the prior 7 days; or

- Urine volume $<0.5 \mathrm{ml} / \mathrm{kg} / \mathrm{h}$ for 6 hours. $^{2}$

The incidence of $\mathrm{AKI}$ is increasing at an alarming rate. $^{3}$ The development and validation of the new AKI diagnostic criteria, namely RIFLE (Risk, Injury, Failure, Loss, and End-stage kidney Disease) and AKIN (Acute Kidney Injury Network) staging are significant advancement in the study of AKI
1. Dr. Nitai Chandra Ray, Assistant Professor, Department Of Nephrology, Community Based Medical College.

2. Dr. Md. Ayub Ali Chowdhury, Professor of Nephrology, National Institute of Kidney Diseases \& Urology, Dhaka.

3. Dr. Md. Abdul Muqeet, Assistant Professor, Department Of Nephrology, Pabna Medical College.

4. Dr. Mahmud Javed Hasan, Associate Professor, Department Of Nephrology, Community Based Medical College.

5. Dr. Ashutosh Saha Roy, Dr. Associate Professor, Department of Nephrology, Mymensingh Medical College

6. Dr. Santana Rani Sarkar, Assistant Professor, Department Of Microbiology, Pabna Medical College.

Address of correspondence:

Email: nitairay@gmail.com

Mobile: 01715108760 
syndrome and permit accurąte comparisons among different studies. ${ }^{3}$ RIFLE/AKIN criteria provide a uniform definition of $\mathrm{AKI}$, and have become the standard for diagnostic criteria.

Stroke is the third leading cause of death after heart disease and cancer in developed countries. ${ }^{4,5}$ The incidence of stroke varies in different countries worldwide. Renal function impairment has been associated with a high prevalence of cardiovascular disease (CVD) including stroke. Although acute stroke and ischaemic heart disease share the same atherosclerotic risk factors, the association of renal function and stroke is poorly investigated. ${ }^{4}$

AKI develops more frequently in older persons, with a higher creatinine and lower glomerular filtration rate (GFR) at baseline and with pre-existent IHD or chronic heart failure (CHF). At the same time, the baseline renal function is a significant independent marker for short-term survival after an acute stroke (even after adjustment for baseline comorbidities) and is a risk factor for subsequent AKI. ${ }^{6}$

The brain and kidney has a similar vascular structure. As a result, microvascular damage to both organs can lead to renal impairment with reduced GFR and asymptomatic or symptomatic brain infarcts with white matter lesions.

For the kidney, damage markers are albuminuria/proteinuria and a reduction in estimated glomerular filtration rate (eGFR), which is also a marker of CKD. On the other hand, small vessel alterations documented by magnetic resonance imaging (MRI) are the markers of brain damage. Recently, clinical investigations have suggested a close relation between these damage markers in the kidney and the brain. ${ }^{11}$ Although mild AKI is clinically reversible, but, endothelial damage with tubular inflammation in the tissue level and activation of intrarenal fibrotic pathways during kidney repair may gradually damage kidney structure, leading to proteinuria, hypertension, and progressive decline in renal function leading to CKD. ${ }^{12,13,14,15}$
Bangladesh is a small country in South Asia with high density of population (an average of 964 inhabitants / square kilometer). ${ }^{16}$ The prevalence of stroke here is 3 per 1000 above the age of 40 years. ${ }^{17}$

Still there are few studies to describe the incidence of $\mathrm{AKI}$ in a single cohort of patients with acute stroke. ${ }^{8}$ The main objective of this study was to find out the incidence and risk factors of $\mathrm{AKI}$ in acute stroke.

\section{Materials \& Methods}

This cross sectional observational study was conducted in Mymensingh Medical College \& Hospital (MMCH) from July 2012 to June 2014. A total of 240 patients with acute stroke, admitted within 7 days of onset of symptoms and above 18 years of age, that fulfilled the inclusion and exclusion criteria were included in this study. A structured case record form was used which included details history, physical findings, results of serial measurement of serum creatinine on admission, on Day 2 \& on Day 7 , CT scan of brain and other relevant laboratory investigations.

The diagnosis of acute stroke was based on WHO definition of stroke, with the support of convincing history, compatible clinical examination finding and confirmed by CT scan of brain. AKI was diagnosed by either an increase in serum creatinine by $\geq 0.3$ $\mathrm{mg} / \mathrm{dl}(\geq 26.5 \mu \mathrm{mol} / \mathrm{l})$ within 48 hours; or increase in serum creatinine to $\geq 1.5$ time's baseline, which was known to have occurred within the prior 7 days. $^{2}$ As baseline serum creatinine (before the present illness) was not known in most of the cases, so serum creatinine level at admission was taken as baseline serum creatinine.

Patients were evaluated meticulously with history, clinical examination and necessary investigations at time of hospital visit. All investigations were done in clinical pathology laboratory, biochemistry laboratory and radiology department of Mymensingh Medical College Hospital.

Patients were classified in AKI group or Non-AKI group based on KDIGO Clinical 
Practice Guideline for Acute Kidney Injury, 2012. Data were analysed according to standard statistical method using computer based software.

\section{Observations and Results}

This study included a total 240 patients with acute stroke, confirmed by CT scan of brain. Out of 240 acute stroke patients 37 patients developed AKI according to "KDIGO Clinical Practice Guideline, 2012" definition of AKI and proportion of AKI was $15.42 \%$ among the acute stroke patients (Table 1).

The mean age of the study subjects was $63.36 \pm 13.86$ years with the youngest and oldest participants were 23 and 90 years \& that of $\mathrm{AKI}$ and Non AKI patients were 65.59 $\pm 13.67 \& 62.95 \pm 13.89$ respectively ( $P$ value $=0.2812$ ) (Table II).

In this study, out of $37 \mathrm{AKI}$ patients majority $(54.05 \%)$ were from $>60$ years age group, $40.54 \%$ between 41 - 60 years and the remaining $5.41 \%$ patients were $<40$ years age group. Among 183 non-AKI patients majority (53.20\%) were from $>60$ years age group. Group, $41.38 \%$ between 41 - 60 years and the remaining $5.42 \%$ patients were $<40$ years age group $\left(\chi^{2}=0.0096 \& P\right.$ $>0.05)$. So, the observed difference of AKI in different age group of the study population was not statistically significant (Table-III).

Out of 145 male patients, 26 (17.93\%) patients developed AKI, and out of 95 female patients $11(11.58 \%)$ patients developed AKI ( $P$ value $=0.1826)$. So, the difference of AKI between male \& female stroke patients was not statistically significant (Table-II).

In this study, majority, 176 (73.33\%) had ischaemic stroke and $64(26.67 \%)$ had haemorrhagic stroke AKI developed in $14(23.44 \%)$ of haemorrhagic stroke patients and $23(12.50 \%)$ of ischemic stroke patients ( $\mathrm{P}$ value $=0.0380)$. So, the observed difference of $\mathrm{AKI}$ in between haemorrhagic \& ischaemic stroke was statistically significant (Table-II).

Among the study population, AKI developed in $9.89 \%$ of smoker stroke patients, $21.14 \%$ of hypertensive stroke patients, $28.11 \%$ stroke patients with IHD, 31.03\% diabetic stroke patients, $33.33 \%$ stroke patients with CKD, $13.33 \%$ patients with dyslipidaemia and $15.22 \%$ with previous stroke. Family $\mathrm{H} / \mathrm{O}$ hypertension, DM and kidney disease was present in $24.44 \%, 30.00 \%$ and $25.00 \%$ of stroke patients, respectively (Table-II).

Among AKI patients, $24.32 \%$ were smoker $70.27 \%$ had hypertension, $29.73 \%$ had IHD, $24.32 \%$ had DM, 37.84\% had CKD, $21.62 \%$ had dyslipidaemia and $18.92 \%$ had previous stroke. $29.73 \%$ AKI patients had family $\mathrm{H} / \mathrm{O}$ of hypertension, $16.22 \%$ patients had family $\mathrm{H} / \mathrm{O}$ of $\mathrm{DM}$, and $13.51 \%$ patients had family $\mathrm{H} / \mathrm{O}$ of kidney disease (Figure 1).

Among the Non AKI patients, 40.39\% were smoker, $47.78 \%$ were hypertensive, $13.79 \%$ had IHD, 9.85\% had DM, 13.79\% had CKD, $25.62 \%$ had dyslipidaemia and $19.21 \%$ had $\mathrm{H} / \mathrm{O}$ previous stroke. Family history of hypertension, DM and kidney disease was present in $16.75 \%, 6.90 \%$ and $7.39 \%$, respectively (Figure -1 ).

Table I: Observed acute kidney injury (AKI) among the entire study patients with acute stroke $(n=240)$.

\begin{tabular}{|l|c|c|}
\hline Group & Frequency & Percent \\
\hline AKI & 37 & $15.42 \%$ \\
\hline Non-AKI & 203 & $84.58 \%$ \\
\hline Total & 240 & $100.00 \%$ \\
\hline
\end{tabular}


Table II: Baseline characteristics of study patients \& sub-groups according to AKI presence.

\begin{tabular}{|c|c|c|c|c|}
\hline \multirow[b]{2}{*}{ Characteristics } & \multicolumn{3}{|c|}{ Frequency } & \multirow[b]{2}{*}{$P$ value } \\
\hline & $\begin{array}{c}\text { Total } \\
(n=240)\end{array}$ & $\begin{array}{c}\text { AKI } \\
(n=37)\end{array}$ & \begin{tabular}{|l|} 
Non AKI \\
$(n=203)$
\end{tabular} & \\
\hline Age (Years) (Mean $\pm S D)$ & $63.36 \pm 13.86$ & $65.59 \pm 13.67$ & $62.95 \pm 13.89$ & $0.2812^{\mathrm{NS}}$ \\
\hline Male (n \%) & $145(100)$ & $26(17.93)$ & $119(82.07)$ & $0.1826^{\mathrm{NS}}$ \\
\hline Female $(n \%)$ & $95(100)$ & $11(11.58)$ & $84(88.42)$ & $0.1826^{\mathrm{NS}}$ \\
\hline Haemorrhagic stroke ( $\mathrm{n} \%)$ & $64(100.00)$ & $15(23.44)$ & $49(76.56)$ & 0.0380 * \\
\hline Ischaemic stroke (n \%) & $176(100.00)$ & $22(12.50)$ & $154(87.50)$ & $0.0380^{*}$ \\
\hline Smoker $(n \%)$ & $91(100.00)$ & $9(9.89)$ & $82(90.11)$ & $0.0639^{\mathrm{NS}}$ \\
\hline Hypertension (n \%) & $123(100.00)$ & $26(21.14)$ & $97(78.86)$ & $0.0118^{*}$ \\
\hline $\begin{array}{c}\text { Ischaemic heart disease (n } \\
\% \text { ) }\end{array}$ & 39 & 11) & (71.79) & $0.0145^{\star}$ \\
\hline Diabetes Mellitus ( $\mathrm{n} \%$ ) & $29(100.00)$ & (31.03) & $20(68.97)$ & $0.0130^{*}$ \\
\hline $\begin{array}{c}\text { Chronic kidney disease (n } \\
\% \text { ) }\end{array}$ & $42(100.00)$ & $14(33.33)$ & $28(66.67)$ & $0.0004^{* *}$ \\
\hline Dyslipidaemia (n \%) & $60(100.00)$ & $8(13.33)$ & $52(86.67)$ & $0.6058^{\text {NS }}$ \\
\hline Previous stroke ( $\mathrm{n} \%$ ) & $46(100.00)$ & $7(15.22)$ & $37(84.78)$ & $0.3861^{\mathrm{NS}}$ \\
\hline \multicolumn{5}{|l|}{ Family history } \\
\hline Hypertension (n \%) & $45(100.00)$ & $11(24.44)$ & $34(75.56)$ & $0.0628^{\text {NS }}$ \\
\hline Diabetes mellitus ( $\mathrm{n} \%)$ & $20(100.00)$ & $6(30.00)$ & $14(70.00)$ & $0.0592^{\mathrm{NS}}$ \\
\hline Kidney disease $(\mathrm{n} \%)$ & $20(100.00)$ & $5(25.00)$ & $15(75)$ & $0.2151^{\mathrm{NS}}$ \\
\hline
\end{tabular}

(Figures within parentheses indicate percentage.)

${ }^{*}=$ Significant at $5 \%$ level of probability $(p<0.05)$.

${ }^{* *}=$ Significant at $1 \%$ level of probability $(\mathrm{p}<0.01)$.

$N S=$ Not significant $(p>0.05)$.

\section{3: Age distribution:}

Table III: Distribution of patients by age ( $\mathrm{n}$ $=240$ )

\begin{tabular}{|c|c|c|c|c|}
\hline Age (Years) & AKI & Non AKI & Frequency & \\
\hline$<40$ & $2(5.41)$ & $11(5.42)$ & $13(5.42)$ & \multirow{4}{*}{$\begin{array}{l}\chi^{2}=0.0096 \\
P=0.9952\end{array}$} \\
\hline $41-60$ & $15(40.54)$ & $84(41.38)$ & $99(41.25)$ & \\
\hline$>60$ & $20(54.05)$ & $108(53.20)$ & $128(53.33)$ & \\
\hline Total & $37(100.00)$ & $203(100.00)$ & $240(100.00)$ & \\
\hline
\end{tabular}

(Figures within parentheses indicate percentage.)

\# Data was analyzed using Chi-square $\left(\chi^{2}\right)$ Test. $\chi^{2}=0.0096 \& P>0.05$. So, the observed difference of $A K I$ in different age group of the study population was not statistically significant.

\section{4: Risk factor distribution:}

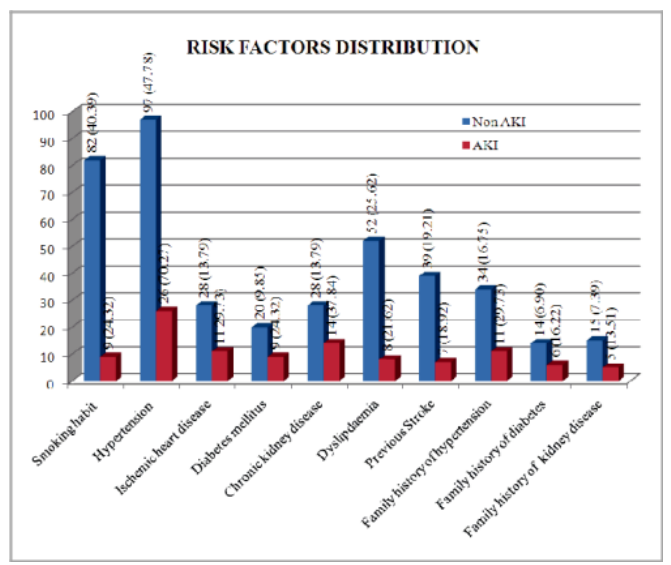

Figure 1: Distribution of risk factors \& their relation with $\mathrm{AKI}$ among the participants (n = 240)

\section{Discussion:}

This cross sectional observational study has reported the incidence of $\mathrm{AKI}$ in acute stroke and has identified the known risk factors and their relation with AKI in patients with acute stroke. In this study, AKI developed in $15.42 \%$ of acute stroke patients (Table I), which was higher than the findings of the study of Covic et al. 2008 \& Bagshaw, SM. 2006 but much lower than that of Tsagalis et al. 2009. In their study, both Covic et al. 2008 \& Bagshaw, SM. 2006 found that the prevalence of AKI was $14.5 \%{ }^{6,19}$ In another study, Tsagalis et al. 2009 found that $26.7 \%$ of acute stroke patients developed AKI. High incidence of $\mathrm{AKI}$ in their study was due to the increased age (mean age $70.3 \pm 11.9$ years.), low baseline GFR, and the use of a highsensitivity definition for the detection of AKI. In their study, only $13.4 \%$ of patients with an eGFR $>60 \mathrm{ml} / \mathrm{min}$ developed AKI, whereas the percentages for patients with an eGFR of 30 to 60 and $<30 \mathrm{ml} / \mathrm{min}$ were 41.2 and $81.0 \%$, respectively. So, preexisting renal dysfunction was a major contributor to the occurrence of $\mathrm{AKI}$ in their study. ${ }^{12}$

In this study, AKI developed more frequently in haemorrhagic stroke than in ischaemic $(23.44 \%$ vs. $12.50 \%, P=0.0380)$ (Table II) 
This difference of $\mathrm{AKI}$ in different types of stroke was statistically significant. This findings were also similar to another study of Tsagalis et al. 2009, they have showed the incidence of AKI was $14.5 \%$ \& was associated with an increased 30-d mortality (43.1 versus $12.8 \%$ in patients without AKI). ${ }^{12}$ In a separate study in 2012, Khatri et al. found that AKI complicated $14 \%$ of ischemic stroke and $21 \%$ of haemorrhagic stroke.

According to this study, AKI developed more commonly in male patient than in female patient $(17.93 \%$ vs. $11.58 \%, P=0.0634)$ (Table II). This sex difference of AKI in stroke patients was not significant. This finding was comparable to the study of Covic et al. 2008. They have showed that AKI developed in $49.7 \%$ of male patients \& $50.3 \%$ of female patients. ${ }^{6}$ This observed difference may be due to less hospital admission of the neglected female patients for better \& earlier medical care which is still prevailing in our society.

In this study, majority of the AKI patients, 20 $(54.05 \%)$ were from $>60$ years of age (Table III) and Mean age was $65.59 \pm 13.67$ years (Table II). These findings were comparable to the study of Covic et al. 2008. They have showed that the mean age of the study subjects was $66.1 \pm 11.5$ years and that of AKI \& non AKI patients was $65.2 \pm 11.5$ years and $71.5 \pm 9.7$ years, respectively. ${ }^{6}$ This higher mean $\pm S D$ of age of the study subject and non-AKI group in their study were due to inclusion of more old aged patients, as prevailing in their society.

In this study, $21.14 \%$ of hypertensive stroke patients, developed AKI ( $P$ value $=0.0118)$ (Table II). This finding was statistically significant and was comparable to the findings of another study by Tsagalis et al. 2009 . They reported that $27.33 \%$ of the hypertensive stroke patients developed AKI. $^{12}$ Similarly, $31.03 \%$ of diabetic stroke patients developed AKI $(P$ value $=0.013)$ (Table II). This finding was statistically significant \& was comparable to the study of Covic et al. 2008. They had observed that AKI developed in $39.8 \%$ diabetic stroke patients. ${ }^{6}$ In a separate study, in 2009, Tsagalis et al. reported that $27.86 \%$ of the diabetic stroke patients developed AKI.12 These observed differences may be due to higher prevalence of hypertensive and diabetic patients in their society, as well as, less awareness of the population \& less availability of regular health care facilities in our society.

Again, AKI developed most commonly in CKD (33.33\%) and then in IHD (28.11\%), previous stroke patients (15.22\%), dyslipidaemia (13.33\%), and in smoker $(9.89 \%)$. Family $\mathrm{H} / \mathrm{O}$ DM was present in $30.00 \%$ of stroke patients and that of hypertension and kidney disease was present in $24.44 \%$ and $25.00 \%$ of stroke patients, respectively. These findings were comparable to the study of Tsagalis et al. 2009. They had found the higher incidence of $\mathrm{AKI}$, eg. $79.20 \% \%$ in IHD, $62.44 \%$ in dyslipidaemia, $25.33 \%$ in smoker, $22.48 \%$ with previous stroke, due to presence of preexisting renal dysfunction among the older population with multiple comorbidities in their study patients. ${ }^{12}$

Among the AKI patients, majority $(70.27 \%)$ had hypertension and then $37.84 \%$ had CKD, 29.73\% had IHD. DM and smoker were both in $24.32 \%$ of AKI patients. Family $\mathrm{H} / \mathrm{O}$ of hypertension, DMand kidney disease was present in $29.73 \%, 16.22 \%$ \& $13.51 \%$ of AKI patients, respectively. These findings are comparable to the findings of Tsagalis et al. 2009. They had also found almost similar prevalence of these risk factors eg. hypertension (71.1\%), smoking (29.20\%), and dyslipidaemia (28.50\%), DM (26.60\%) and IHD (21.6\%) of AKI in acute stroke. ${ }^{12}$ The study had several possible clinical implications and had identified some independent risk factors of $\mathrm{AKI}$, in particular age, sex, smoking, hypertension, IHD, DM, CKD and types of stroke. So, the risk score could be easily calculated to predict the risk of acute kidney injury in acute stroke patients.

Patients with AKI have a higher risk of later development of CKD. So prevention, early diagnosis and proper management of AKI are of utmost importance to reduce the 
related morbidity and mortality of acute stroke patients and also to reduce the economic burden of the patients by decreasing the need for Dialysis.

Nonetheless, this study has several limitations. This is a tertiary hospital based study and included a small sample size due to time \& cost limitations. So, this study may not reflect the real scenario of the country. Moreover, very few patients had their documented baseline renal function before admission, it is unclear to what extent the first creatinine reflects "baseline" kidney function.

\section{Conclusion:}

AKI is a common complication after acute stroke. Multiple additional risk factors are responsible for development of AKI during acute stroke. Hypertension, CKD, IHD and $\mathrm{DM}$ are the most prevalent risk factors. Smoking habit, previous stroke, dyslipidaemia and family history of hypertension, diabetes mellitus \& kidney disease are also responsible for AKI during acute stroke. So identification \& avoidance of these risk factors in the early hours of hospitalization is of utmost importance to prevent the development of AKI in acute stroke patients. Nationwide study with random sampling is necessary for generalization of the findings and to identify the precise mechanism, risk factors and actual outcome of acute kidney injury that develop in patients with acute stroke.

\section{References:}

1. Glassock RJ, Massry SG \& Humes HD. Acute renal failure including cortical necrosis. In: Text Book of Nephrology. 4th edition. Philadelphia: Lippincott Williams and Wilkins. 2001. p. 968-69.

2. KDIGO. Clinical Practice Guideline for Acute Kidney Injury. 2012; 2 (1): 19.

3. Bruetto RG, Rodrigues FB, Torres US, Otaviano AP, Zanetta DMT et al. Renal function at hospital admission and mortality due to acute kidney injury after myocardial infarction. PLoS One. 2012; 7 (4): e35496.
4. Tsagalis G, Akrivos T, Alevizaki M, Manios E, Stamatellopoulos $K$, Laggouranis $A$ et al. Renal dysfunction in acute stroke: an independent predictor of long-term all combined vascular events and overall mortality, Nephrol Dial Transplant.2009; 24: 194-200.

5. Collins TC, Petersen NJ, Menke TJ, Souchek $J$, Foster W, Ashton CM. Short-term, intermediate-term, and long-term mortality in patients hospitalized for stroke. I Clin Epidemiol. 2003; 56: 81-7.

6. Covic A, Schiller A, Mardare NG, Petrica L, Petrica M, Mihaescu $A$ et al. The impact of acute kidney injury on short-term survival in an Eastern European population with stroke. Nephrol Dial Transplant. 2008; 23: 2228-34.

7. O'Rourke MF \& Safar ME. Relationship between aortic stiffening and microvascular disease in brain and kidney: cause and logic of therapy, Hypertension.2005; 46: 200-4.

8. Ikram MA, Vernooij MW, Hofman A. Kidney function is related to cerebral small vessel disease, Stroke. 2008; 39: 55-61.

9. Khatri $M$, Wright $C B$, Nickolas TL. Chronic kidney disease is associated with white matter hyperintensity volume: the Northern Manhattan Study (NOMAS), Stroke. 2007; 38: 3121-6.

10. Seliger SL, Longstreth WTJ, Katz R. Cystatin $C$ and subclinical brain infarction, $J$ Am Soc Nephrol. 2005; 16: 3721-7.

11. Mogi $M$, Horiuchi $M$. Clinical Interaction between Brain and Kidney in Small Vessel Disease, SAGE-Hindawi Access to Research Cardiology Research and Practice. 2011; 5. Article ID 306189.

12. Tsagalis $G$, Akrivos $T$, Alevizaki M, Manios $E$, Theodorakis $M$, Laggouranis $A$ et al. Long-Term Prognosis of Acute Kidney Injury after First Acute Stroke Clin J Am Soc Nephrol.2009; 4 (3): 616-22.

13. Basile DP, Donohoe D, Roethe K, Osborn $\mathrm{JL}$. Renal ischemic injury results in permanent damage to Peritubular capillaries and influences long-term function. Am J Physiol Renal Physiol. 2001; 281: 887-9. 
Original Article

14. Basile DP. The endothelial cell in ischemic acute kidney injury: Implications for acute and chronic function. Kidney Int. 2007; 72:151-6.

15. Spurgeon-Pechman KR, Deborah $L$, Donohoe $D L$, Mattson $D L$, Lund $H$, James L, Basile DP. Recovery from acute renal failure predisposes hypertension and secondary renal disease in response to elevated sodium, Am J Physiol

Renal Physiol.2007; 293: 269-78.

16. Bangladesh Bureau of Statistics. Population and housing census 2011, Preliminary result, July 2011; 8.

17. Mohammad $Q D$, Habib M, Mondal BA, Chowdhury RN, Hasan MH, Hoque MA et al. Stroke in Bangladeshi Patients and Risk Factor, Mymmensingh Medical Journal.2014; 23(3):520- 5.

18. Ali T, Khan I, Simpson W, Prescott G, Townend J, Smith $W$ et al. Incidence and outcome in acute kidney injury: a comprehensive population based study, J Am Soc Nephrol.2007; 18: 1292-8.

19. Bagshaw SM. Short- and long-term survival after acute kidney injury, Nephrol Dial Transplant. 2008; 23: 2126-8. 